\title{
Aware Migrants: The role of information campaigns in the management of migration
}

$1-12$
C The Author(s) 2019
Article reuse guidelines:
sagepub.com/journals-permissions
DOI: 10.1 I $77 / 0267323$ I I 9886 I64
journals.sagepub.com/home/ejc

@SAGE

\section{Pierluigi Musarò \\ University of Bologna, Italy}

\begin{abstract}
Taking as a starting point studies on the biopolitics of bordering, as well as media studies, this article explores how information campaigns deter potential migrants and refugees from leaving their countries depict them in very specific ways, operating as 'new bordering practices' that are in conjunction with extraterritorial border policies. This article probes this question through the example of a specific information campaign - Aware Migrants (2016) - funded by the Italian Government and managed by International Organization for Migration (IOM) to dissuade potential newcomers from attempting the journey across the Mediterranean Sea. As the analysis of Aware Migrants makes clear, it contributes to normalizing a transnational imaginary into a militarized borderscape comprising places of violence and death, exploitation and detention, which is part of the complex dichotomies of care and control, proper of contemporary border regimes. Finally, the article sheds light on how these symbolic bordering practices contribute to nurturing a 'compassionate repression' that increasingly and silently legitimizes the difference between the 'us' (the figure of the citizen) and the 'them' (the figure of the foreigner).
\end{abstract}

\section{Keywords}

Aware Migrants, border regime, bordering practices, information campaigns, migration

Ahmed drives to Beirut and boards a plane with his family. Casting his eyes to the midnight sky, despite all he has lost, he offers thanks to the smugglers that made it all possible, the criminal heroes who allow him to start his life anew in Europe

\section{Corresponding author:}

Pierluigi Musarò, Department of Sociology and Business Law, University of Bologna, 40 I 26 Bologna, Italy. Email: pierluigi.musaro@unibo.it 


\section{Introduction}

Articulating freedom of movement within the Schengen space with a variable geometry of control of the external frontiers, the 1990s are marked as the period when the European Union (EU) began tightening and militarizing its borders (Bigo, 2002; Mezzadra and Nielson, 2013), justifying its massive investments in border controls through the narratives of national security - combating human smuggling and potential terrorists (Vaughan-Williams, 2015) - and humanitarian action - rescuing lives and protecting asylum seekers' human rights (Musarò, 2017; Walters, 2011).

The 1990s is also the period in which Europe started to implement the so-called awareness campaigns to deter irregular migration. These campaigns are considered an essential tool in fighting human trafficking and undocumented migration, as they contribute to raising awareness among potential victims regarding the risks of being caught in criminal networks and thus reduce their vulnerability. Several states, supported by the International Organization for Migration (IOM), have launched numerous campaigns to inform the population of sending regions of the risks of migrating, mostly in central and eastern Europe - Romania (1992-1996), Albania (1992-1995), and Ukraine (1998) with an increase since 2000 in northern and sub-Saharan African countries like Morocco, Gambia, Ghana, Senegal, and Nigeria (Nieuwenhuys and Pécoud, 2007).

In their attempt to reduce emigration before migrants reach the border by convincing them not to leave their home, these campaigns complement traditional methods of migration control, such as the surveillance of borders. As Nieuwenhuys and Pécoud (2007) argue, 'By raising awareness of the risks of migration and the harsh realities of life in destination countries, information campaigns should counter these illusions and thereby jeopardize smugglers' business' (p. 1675).

Although international agencies such as UNHCR (United Nations High Commissioner for Refugees) and IOM acknowledge that asylum seekers travel side by side with economic migrants fleeing from poverty and seeking better opportunities, this blurred distinction between forced and voluntary migration is at the basis of policy-making and is crucial for the future of newcomers.

In order to prevent arrival of irregular migrants and asylum seekers, EU states have invested massively in border control and made bilateral agreements for externalization of borders (the EU-Turkey agreement on March 2016 and the Memorandum of Understanding between Italy and Libya on February 2017, among others). Furthermore, successive European governments from both sides of the political spectrum have enacted draconian measures to prevent, deter, and punish those engaged in the smuggling of migrants - both as smugglers and smuggled migrants (Andersson, 2014).

The formal definition of the smuggling of migrants comes from the United Nations Convention against Transnational Organized Crime (UNTOC), which has been ratified by 141 states. It describes smuggling as 'the procurement, in order to obtain directly or indirectly, a financial or other material benefit of the illegal entry of a person into a State Party of which the person is not a national or a permanent resident'. ${ }^{1}$ Therefore, smuggling is seen as a crime against the state, not against a person. With Tinti and Reitano (2016) we can argue that smuggling, after all, 'is often a consensual agreement between the smuggler and the migrant. More often than not, a smuggler is providing a service and meeting a demand for illicit movement' (p. 37). 
By contrast, trafficking, which is internationally recognized as a human rights violation, is a non-consensual relationship that involves the ongoing exploitation of another human being in forced labour or forced prostitution. It is defined as 'the recruitment, transportation, transfer, harbouring or receipt of persons, by means of the threat or use of force or other forms of coercion, abduction, or fraud or deception'. ${ }^{2}$

Nevertheless, in the strategies of border control, the terms are often used interchangeably, to the point that nowadays facilitating irregular migration is considered to be an organized crime. This semantic confusion is particularly evident in information campaigns to deter undocumented migration. Despite the importance to inform would-be migrants on the risks of their adventure, these campaigns not only contribute to create a semantic confusion between the smuggling and the trafficking realities, but they also contribute to categorize migrants as voluntary/forced, desirable/undesirable and legal/ illegal. In their attempt to prevent arrivals before migrants cross the border, these campaigns contribute to normalize the extraterritorial border by negatively stereotyping migration, or even criminalizing it a priori.

This semantic confusion goes hand in hand with facile and counterproductive narratives that portray smugglers as villains, exploitative, profit-driven criminals, and the migrants as the vulnerable, desperate, passive victims. Thus, it is fundamental to unveiling the typical narratives of information campaigns in order to go beyond the stereotyped imaginary of the humanitarian or securitarian approach. These approaches not only deny the difference between people who have the right to ask for asylum and economic migrants who cross the border without a regular visa, but they also reduce the complex narrative of human migration into simple dichotomies of good and evil, in turn fostering bad policies that put migrants at risk while empowering criminal organizations.

Moving from these assumptions, this article aims at researching how these campaigns depict irregular migrants and refugees and how their use of images contributes to the aim of governing migration. This article probes this question through the example of a specific information campaign - Aware Migrants (2016) - funded by the Italian government and managed by IOM to dissuade potential newcomers from 15 African countries (including the top three asylum seeker suppliers to Italy - Nigeria, Eritrea and Sudan) from attempting the perilous journey across the Mediterranean Sea. Drawing upon the high number of people who had been killed during the same year while attempting to reach Italy's southern shores, the Aware Migrants campaign features news, articles and powerful video testimonials from migrants who had to endure physical and sexual abuse from human traffickers along the way.

Taking as a starting point studies on the biopolitics of bordering, as well as media studies, this article advances the hypothesis that for achieving its goal of deterring wouldbe migrants and refugees from leaving their countries, the campaign depicts them in very specific ways, operating as 'new bordering practices' that are in conjunction with extraterritorial border policies.

Finally, the article sheds light on how these symbolic bordering practices contribute to nurturing a 'compassionate repression' (Fassin, 2012) that increasingly and silently legitimizes the difference between the 'us' (the figure of the citizen) and the 'them' (the figure of the foreigner). 


\section{The symbolic dimensions of bordering practices}

There is now a rich literature exploring the extraterritorial border management, while focussing on two different aspects of this practice: the securitization of territory adjacent to physical borders and the topologies of biopolitics governing racialized bodies.

Several scholars have documented the extraterritorial 'stretching of borderwork' (Casas et al., 2010) through transnational statecraft manifesting securitized territories as 'buffer zones', alternatively defined archipelagos (Mountz, 2011) or borderlands (Agier, 2016), among others. At the same time, research documenting the biopolitics dimension of the border management tends to emphasize the disciplining of undesired migrants through the toll deflection, detention, surveillance and deportation takes on migrant bodies (Agamben, 1998; Ticktin, 2011).

On the other hand, what requires greater attention is how states attempt the symbolic control of unwanted migrants, the use of extraterritorial subjugation as a practice of preemptive border security and how governments implement border externalizations through extraterritorially acting upon people's perceptions of migration, including depicting irregular migration in a negative light. Following this perspective, awareness campaigns to discourage irregular migrants can be intended as efforts by states to govern international migration through spreading imaginaries that symbolically reshape certain spatial associations. Yet, these symbolic and imaginary dimensions of border externalization have received little scholarly consideration, and detailed analysis of anti-irregular migration campaigns is lacking (Collyer and King, 2015; Watkins, 2017).

Beyond the physical aspect of the border, thus, it is fundamental to consider the symbolic aspects of it. Images and discourses reporting the European ways to tackle the 'migration crisis', while illegalizing those who attempt to cross the border - focussing on their endeavour in terms of risks, death, prohibitions, acts of breaking the law, failure of the arrival - are part of how the media and communication contribute to shape the border (Cuttitta, 2014; Chouliaraki and Georgiou, 2017; Musarò and Parmiggiani, 2017).

The media portrayals of people crossing the border, through narratives and images of security and salvation, for example, can be understood as representational barriers that construe their identities as 'desirable' or 'undesirable'. This is what Chouliaraki and Musarò (2017) term the 'narrated' border, which is part of the wider 'mediatized border', intended as a regime of reception characterized by the fusion of caring compassion for and military protection from mobile populations.

As we have argued in our empirical description of the European border as a site of both repelling threats and tender-hearted care, 'instead of simply referring to representing through the media, the mediatization of the border refers, then, to the ways in which the practices, identities and emotions of the border are performed and constituted through media technologies' (Chouliaraki and Musarò, 2017: 2).

In other words, assuming mediatization as a process in which 'the media exert a particularly dominant influence on other institutions' (Hjarvard, 2008: 13), we can describe the mediatized border as a techno-affective network of mediations around migrants and refugees, where emotions of fear and empathy co-exist through digital connectivities, ritualizing our relationship with the other through discourses of difference and superiority. 
To capture the symbolic and affective role of digital media in managing human mobility, we need to investigate the border not as a place, rather as a process, a socially constructed and shifting structure of practices and discourses that produce norms of difference and exclusion across bodies and voices of would-be migrants, with a view to sustaining projects of geo-political sovereignty (Chouliaraki and Georgiou, this volume).

As Vaughan-Williams (2015) highlights, the border is always 'a process of bordering' that 'seeks to rhetorically identify and control the (very) mobility of certain people, services and goods that operate around its jurisdiction' (p. 6). As a technologically driven process of 'rhetorical identification and control', the process of bordering thus systematically produces its own 'discursive or emotional landscapes of social power' (Paasi, 1996: 63).

These affective spatial imaginaries are extraterritorially disseminated by the states to symbolically normalize certain territorial relationships. As Watkins (2015) suggest, we can intend spatial imaginaries as 'performative discourses, socially held narratives about spaces and places circulated in language and performed in material practice, that work to normalize symbolic associations between people, spaces, and places' (p. 509). Through their normalization, spatial imaginaries (re)shape social perceptions about places even among people who have not visited them. In so doing, these imaginary geographies are used as a 'positive power' by the states to normalize human behaviour - a power that contributes to aid the policing of migration, through the shaping of the choices, desires, needs and wants of people (Dean, 2010).

Using this schema, information campaigns to deter irregular migrants should be understood as new forms of delocalized migration control. These can be intended as new bordering practices that work extending the subject-making power of the state beyond its sovereign borders to redefine the 'truth' of irregular migration. A redefinition that aims to modify the 'choices, desires, needs, and wants' of potential irregular migrants in ways discouraging them from migrating (Watkins, 2017: 284).

According to this perspective, we can argue that traditional methods of migration control, such as the surveillance of borders, are thereby complemented by attempts to convince migrants not to leave their home. Thus, to understand how information campaigns contribute to prevent arrivals before migrants reach the border, it is fundamental to explore the ways in which these new bordering practices are part of the complex dichotomies of care and control, the absence and presence of law, transparency and darkness, solidarity and indifference, which mark contemporary border regimes.

\section{Aware Migrants}

Focussing on the ongoing tragedies in the Mediterranean Sea, on July 2016, Italy's Interior Minister, Angelino Alfano, launched a media campaign aimed at dissuading African migrants from making the unsafe journey to Europe over the Mediterranean. ${ }^{3}$ Developed in partnership with the IOM, Aware Migrants was realized by the Horace communication agency and was launched in three languages - English, French and Arabic - on various platforms, including its own website, Facebook, YouTube, Twitter and Instagram. 
When it was launched, the campaign sought to warn would-be migrants about the costs and dangers associated with migrant smuggling, and the harsh conditions and consequences they may face en route and on arrival in Europe. In its first version, the campaign was based mainly on the video testimonies of the survived victims to emphasize the risk of dying in the desert or drowning in the sea, along with traumatized memories of dangerous experiences, generating emotions of panic, sadness, hopelessness and tragedy among potential irregular migrants. All the short videos (about 1 minute long) start with the written sentence 'The story you are about to hear is true', with the name and the age of the storyteller (i.e. Thierno, 18 years old; Abdul, 23 years old, etc.), who starts to tell his or her personal tragic story, emphasizing the violence suffered along the route, the unexpected surprise of corrupted policemen asking for money or forcing her to have sex, the physical danger of clandestine boat travel to Europe, the terrible time spent in an overcrowded prison, the inhumane death of a friend killed by criminal traffickers and so on. The format of the videos is always the same: a close-up shot of the sad person's face speaking on a dark and empty background, a deep silence sometimes broken by far away voices. Usually the storyteller watches the camera directly. In some cases, she or he is turned and we can only see the hair or a darkened head; it usually happens when the protagonist is a victim of sexual violence.

At the end of the intense personal tales, on a black screen appears a sign reporting data such as 'Every year thousands of women are victims of sexual violence on their way to Europe' (after Jessica's story), or 'In 2016, as of today, an average of 480 migrants have died at sea per month' (at the end of Tchamba's tale) and so on. Right after, the protagonists appear again for a few second with his or her hand on the heart, and next to him or her the written on the screen overlay 'Be aware, sister' or 'Be aware, brother' (depending if the protagonist is a woman or a man).

A few months after the launch, the website of the campaign was enriched by two more sections: News and Media. In the first section, there are articles reporting terrible news on the risks of the journey and warning would-be migrants on the criminal behaviour of the smugglers and traffickers - some titles are as follows: 'Unimaginable Horrors in Libya's Migrant Detention Centres', 'Sisters support Nigeria's migrants traumatized by trafficking' or 'Organ trafficking in Egypt: "They locked me in and took my kidney"'. In the Media section, we find spots, music and videos that convey the same messages, warning the spectators to not risk their lives or challenging death.

Less than 1 year after the official launch, other European countries started to contribute to the campaign. In particular, the contribution of the German Federal Foreign Office allowed the launch of the second phase of the project: 'Engaging West African Communities'. This phase, which for the moment is being implemented in Senegal, Ghana and Niger, 'builds, as IOM reports, on the previous one reinforcing the awareness-raising efforts and emphasizing the voices of the returnees who could provide and share their experiences with their home communities to prevent others from running the same risks'. ${ }^{4}$

Probably due to these further contributions, the Aware Migrants' website has been enriched with new sections, including articles and videos. More specifically, the section Stories has been split in two different containers: Testimonies in Italy and Stories along the Route. While the videos of people in Italy have all the same format (which I have 
previously described), the protagonists of this second section tell their stories in different locations and styles. Sometimes they are sitting in a rural African road, showing their children on the smartphone while talking about their dream to go back home; other times they are traditionally dressed, walking in a market among local people, telling of their terrible experience in Libya and the way they escaped death. In this section, the videos last longer (some of them even more than 6 minutes), and even if the stories are always related with pain, false expectations and traumatic experiences, the atmosphere of the short movies is warmer and more relaxed. These are micro movies with montage of different scenes: often there is a dramatic music in the background, and it is not rare to see the protagonists smiling, especially when they refer to their relatives at home or they talk about the possibility of a new life.

The different style of the videos, the fact that some of them are shot in IOM's transit centres and that all report the blue logo of IOM, the content of their stories, and the expression of the protagonists' faces lead me to suppose that the narrators are beneficiaries of an IOM's Assisted Voluntary Return and Reintegration (AVRR) programmes. These programmes ensure the financial and social reintegration of individuals who decide to returning back home, through a cooperation with all stakeholders in origin and reception countries.

Within the visual economy of the campaign, the narratives of these protagonists are less desperate and pessimistic than the testimonies in Italy. While in the Italian section the leitmotiv of the tales is the horrific personal experiences and the normative advise to 'be aware', prevalent in this section are narratives of anger against the traffickers, gratitude towards God who made them survive and a quiet sense of redemption expressed through the desire to return to their families in their countries of origin. Among others, there is a video by Kofi Kinaata, a famous Ghanaian musician and songwriter, whose paradigmatic title is 'No Place Like Home'. In this video, the images of the 'cool' musician singing 'Say no to irregular migration' are alternated with scenes of local young people discussing about travelling to Europe through Libya. After a long discussion with several warnings to change their mind and invest their money at home, at the end of the video we discover that one of them died along the route while the family was not even informed about that.

Both sections present videos aiming at raising awareness on what is happening along the main routes from East/Western Africa across the desert and the Mediterranean. At the same time, while the 'Italian' section is more static and focused on the tragic memories of the survivors warning the 'brothers' and 'sisters' that irregular migration 'it's a road with no return' - as Tchamba says - the other section seems more oriented to discourage the would-be migrants through stories of despair and hope, anger and intimate dreams presented by the voices of 'returning migrants, who can become themselves communication agents and whose experiences can cut through the suspension of disbelief, common among potential migrants believing to succeed where others failed', ${ }^{5}$ as one of IOM's objective states.

A similar more positive attitude is also present in the news related with Opportunities in Africa, a website's sub-section of Alternatives, which was included in the website when the second phase of the project started. Here, practical chances to invest in African countries (training courses, call for ideas, programmes for local entrepreneurs, etc.) 
alternate with successful stories of African returnees who 'have a clearer vision of the future' thanks to the support of IOM (as declared by Koné Amara, a 28-year-old Ivorian stopped in Tunisia while trying to reach Europe), and solemn calls to 'young Africans to stay in their countries to work and earn their living', by famous singers like Coumba Gawlo Seck or Ashraf Sidrawi. This is the part that most corresponds to IOM's declared objective to 'support community stabilization initiatives in countries of origin and promote information on positive alternatives, including socio-economic opportunities for youth in West African countries'.

According to United Nations Office on Drugs and Crime (UNODC) and IOM's toolkits to combat smuggling of migrants, ${ }^{6}$ all these factors can be considered fundamental to ensure trustworthiness and improve effectiveness of information campaigns. Developing the campaigns in the countries of origin with local institutions and nongovernmental organizations (NGOs), presenting successful solutions rooted in local communities and bottom-up, involving would-be migrants directly, engaging local protagonists like singers and pop stars, including both digital and non-digital resources, harnessing the power of existing resources available for them are all factors that contribute to the effectiveness of the campaign.

Another factor the just mentioned toolkits point as fundamental to combat the smuggling of migrants is making available avenues for legal migration and presenting them as significant alternatives. This is one of the most problematic aspects of the Aware Migrants campaign. In fact, in its website it includes a page on Regular Channels, presenting legal ways to enter and stay in some EU countries. But this section appears as the most poor and inadequate to expectations of would-be migrants. In addition to the fact that the information is related to only seven countries (probably the ones that financially support the campaign), while the Schengen Area is an area comprising 26 EU states, the short description of the procedures on how to apply for a visa is very generic and often alternates with warnings on entering illegally in the country, including information on illegal presence, rejection and expulsion.

Moreover, the information on how to get a regular visa is mainly focused on describing how the national migration agencies are the 'expression of the national democracy' (Belgium and Sweden), or showing that 'the national policy on foreign nationals is fair' (Netherlands), with almost no references to the right and the procedures to apply for asylum.

This is a particularly problematic factor when we consider the impacts of the campaign in deterring smuggled migrants, many of whom have the right to seek asylum in Europe. As UNODC states, if designed and executed properly, awareness campaigns about the causes and consequences of migrant smuggling have the potential to prevent 'the higher human cost resulting from unscrupulous methods and motives of migrant smugglers', as well as reducing or avoiding 'the high cost and risk of launching transnational investigations and prosecutions'. ${ }^{7}$ But concerns arise when information campaigns are used to deter people who are fleeing persecution, torture, discrimination, war, poverty and other humanitarian crises. More generally, using fear mongering messages (shock and sorrow) to symbolically connect irregular migration to financial and familial ruin, as well as by emphasizing the illegal aspects of migrant smuggling and labelling smuggled migrants as illegals, this campaign may have the effect of deterring persons in 
desperate situations, facing prosecution, torture, discrimination and human rights abuses, from exercising their right to seek asylum by keeping them at a distance.

\section{Geographies of exclusion}

This article has not attempted to demonstrate information campaigns' ability to deter migration. Rather, these campaigns have been analysed as communicative mediums disseminating symbolic narratives about, and associations between, places and spaces. What is clear from the visual and textual analysis of Aware Migrants is that it depicts would-be migrants and smugglers in very specific ways that complement migration policies while creating an outside of the nation. The ways images and messages frame current tragedies to raise awareness on what is happening in the Mediterranean do not only report on the world 'out there', but also constitute this world in meaning, opening up the space for certain forms of intervention and the production of specific types of subjects. Consequently, this imaginary border is transformed into a social reality experienced by the persons who are the 'expelled' of this particular negative story of the nation. At a symbolic level, these campaigns are similar to humanitarian spaces - camps and, more widely, the spaces of humanitarian intervention - described by Agier (2016) as 'partial delocalization of sovereignty', because they 'establish their spaces and find their legitimacy in the interstices of national borders, the "outside" of nation-states' (p. 52).

As the analysis of Aware Migrants presented above makes clear, it contributes to normalizing a transnational imaginary into a militarized borderscape comprising places of violence and death, exploitation and detention. The ways this symbolic bordering practice depicts potential migrants and smugglers adopting humanitarian language to justify harsh policies as a way to prevent exploitation of migrants by smugglers, and end drowning deaths at sea, can be considered integral part of a complex logic of risk and benevolence, of threat and vulnerability, allowing for a military-humanitarian response.

For example, the campaign depicts a border regime (De Genova et al., 2015) that is turning the Mediterranean into a mass grave in depoliticizing terms as a humanitarian crisis with its root causes always attributed to troubles elsewhere, usually in desperate and chaotic places beyond the borders of Europe (Balibar, 2016). As such, it is in the continuity of the campaign accompanying the military-humanitarian operation Mare Nostrum, launched by the Italian Navy in 2014, which performed the spectacle of the 'humanitarian battlefield' (Musarò, 2017).

Meanwhile, omitting that the visa restrictions and border controls established by European states require such journeys to be undertaken with the assistance of human smugglers and other members of the burgeoning illicit 'migration industry' (Andersson, 2014), the campaign is designed within a narrow and restrictive security framework that depicts smugglers as criminal groups and opportunistic individuals who are generating profits in the billions, while putting victims' life at risk. In doing so, the campaign disqualifies migration at large and presents it as the choice of the ignorant, the stupid or the mindless, neglecting the degree of agency and control that the migrant has over his journey. While it may be beneficial or politically expedient to portray the migrant as a vulnerable victim and the smuggler as a cruel, exploitative controller, this is a largely disingenuous characterization. Although some smugglers turn out to be traffickers, who, after luring 
unsuspecting clients with false promises of a better life, subject them to exploitation and abuse, the transactional relationship with the smuggler is often chosen on a voluntary base and it is perceived as a mutual benefit. And, as Tinti and Reitano (2016) argue, 'they are the only one who help the most desperate among us escape the inadequacy, hypocrisy and immorality that run through our current international mobility system' (p. 19).

Furthermore, these stereotyped narratives of villains and victims don't allow us to examining smugglers dispassionately for what they are: service providers in an era of unprecedented demand. It is certainly true that smugglers profit from the desperation of others, but it is also true that in many cases smugglers save lives, create possibilities and redress global inequalities:

For many smuggled migrants, the illegal services offered by their smugglers represent the only way to escape death or other forms of harms; for others, migrant smuggling is seen as the only or most immediate avenue to a better life for themselves or that of their family. (Schloenhardt and Philipson, 2013: 3)

Beyond the focus on trafficking risks, the dangers of the journey are emphasized by visual and textual evidence of the unattractive fate of undocumented migrants in Europe. Assuming that migration is a decision often based on false expectations ("many migrants leave their home without a concrete project of precise idea of the socioeconomic and political situation of their country of destination', Aware Migrants declares on the website), the warning here is that migrants who abuse immigration laws, asylum procedures or welfare schemes are exposed to severe consequences. In fact, the news, articles and videos of the campaign advise potential newcomers that even if they are strong and lucky enough to reach our shores, they need to convince us that they are really in need of international protection. As the Italy's Interior Minister affirmed during the press conference of the campaign's launch, 'Europe's migrant crisis is an epochal struggle', and 'obviously, we pride ourselves on welcoming all those fleeing war'. Nevertheless, advising that ' $60 \%$ of asylum seekers in Italy had their applications rejected in 2015 because they were not deemed by authorities to be true refugees fleeing war', he noted that Italy and the rest of the EU 'must speed up the repatriation of migrants with no legal residency rights, otherwise the bloc's migrations policies will collapse' ${ }^{8}$ Thus, the stories of survivors who experienced terrible dangers to come to Europe appear as integral tools of the 'necropolitical' approach (Mbembe, 2003) to tackle the so-called migrant crisis. In the words of the Minister Alfano, as in the images and texts of the campaign, it seems clear that asylum seekers have not been invited, they are unwanted, undeserved and that we - Europeans - are not willing to welcome many of them. In so doing, the Aware Migrants' narratives through which the Italian Government seeks to 'manage the perception' of potential illegal(ized) migrants contribute to nurturing a 'compassionate repression' that legitimizes the difference between us and them.

Finally, despite the fact that - as several studies show (Browne, 2015; Pécoud, 2010) - these campaigns have limited, if any, effect on migrants' decisions to leave, these initiatives represent a further example of how media performances contribute to shaping the Mediterranean border as an emotional and physical setting in which fears and insecurities can be used to produce and perpetuate the colonial geographies of exclusion. 
While it is evident that awareness campaigns will not be effective in preventing migrant smuggling unless would-be migrants see meaningful alternatives, it is less clear to what extent this dehumanization of irregular migrants do little to counteract the xenophobic sentiments that characterize much of the public debate and media reporting on the topic of migrant smuggling in Europe. Obscuring the causes of irregular crossing the border as well as the humanity of people doing it not only diverts audiences' attention away from the ethical and political responsibilities of the European governments, but it also contributes to criminalize international solidarity and broadly weaken the articulations of a just society and the respect of human rights.

\section{Funding}

The author(s) disclosed receipt of the following financial support for the research, authorship, and/ or publication of this article: This research is co-funded by the European Union under the Erasmus + Programme Jean Monnet Activities (599660 EPP-1-2018-1-AU-EPPJMO-Network).

\section{Notes}

1. Protocol against the Smuggling of Migrants by Land, Sea and Air, 2004, art 3(a).

2. Protocol to prevent, Suppress and Punish Trafficking in Persons, Especially Women and Children, 2004, art. 3(a).

3. https://awaremigrants.org/

4. https://italy.iom.int/en/aware-migrants

5. https://italy.iom.int/en/aware-migrants

6. Toolkit to Combat Smuggling of Migrants, the International Framework for Action to Implement the Smuggling of Migrants Protocol and the Model Law against the Smuggling of Migrants.

7. UN Doc CTOC/COP/WG.7/2012/2.

8. http://www.interno.gov.it/it/notizie/aware-migrants-campagna-informativa-evitare-viaggiosperanza-diventi-incubo

\section{References}

Agamben G (1998) Homo Sacer: Sovereign Power and Bare Life. Stanford, CA: Stanford University Press.

Agier M (2016) Borderlands: Towards an Anthropology of the Cosmopolitan Condition. Cambridge: Polity Press.

Andersson R (2014) Illegality, Inc. Clandestine Migration and the Business of Bordering Europe. Oakland, CA: University of California Press.

Balibar (2016) Europe, crise et fin? Paris: Le Bord de l'Eau.

Bigo D (2002) Security and immigration: Toward a critique of the governmentality of unease. Alternatives: Global, Local, Political 27(1): 63-92.

Browne E (2015) Impact of communication campaigns to deter irregular migration. GSDRC Helpdesk Research Report No. 1248. Birmingham: GSDRC.

Casas M, Cobarrubias S and Pickles J (2010) Stretching borders beyond sovereign territories? Mapping EU and Spain's border externalization policies. Geopolitica(s) 2(1): 71-90.

Chouliaraki L and Georgiou M (2017) Hospitability: The communicative architecture of humanitarian securitization at Europe's borders. Journal of Communication 67(2): 159-180.

Chouliaraki L and Musarò P (2017) The mediatized border: Technologies and affects of migrant reception in the Greek and Italian borders. Feminist Media Studies 1: 16. 
Collyer M and King R (2015) Producing transnational space: International migration and the extraterritorial reach of state power. Progress in Human Geography 39(2): 185-204.

Cuttitta P (2014) Borderizing the Island. Setting and narratives of the Lampedusa border play. ACME: An International E-Journal for Critical Geographies 13(2): 196-219.

De Genova N, Mezzadra S and Pickles J (2015) New keywords: Migration and borders. Cultural Studies 29(1): 55-87.

Dean M (2010) Governmentality: Power and Rule in Modern Society. Los Angeles, CA: SAGE.

Fassin D (2012) Humanitarian Reason: A Moral History of the Present. Berkeley, CA: University of California Press.

Hjarvard S (2008) The mediatization of society: A theory of the media as agents of social and cultural change. Nordicom Review 29(2): 105-134.

Mbembe A (2003) Necropolitics. Public Culture 15(1): 11-40.

Mezzadra S and Nielson B (2013) Border as Method, Or, Multiplication of Labor. London: Duke University Press.

Mountz A (2011) Seeking Asylum: Human Smuggling and Bureaucracy at the Border. Minneapolis, MN: University of Minnesota Press.

Musarò P (2017) Mare Nostrum: The visual politics of a military-humanitarian operation in the Mediterranean Sea. Media, Culture \& Society 39(1): 11-28.

Musarò P and Parmiggiani P (2017) Beyond Black and White: The role of media in portraying and policing migration and asylum in Italy. Revue Internationale de Sociologie 27(2): 241-260.

Nieuwenhuys C and Pécoud A (2007) Human trafficking, information campaigns, and strategies of migration control. American Behavioral Scientist 50(12): 1674-1695.

Paasi A (1996) Territories, Boundaries and Consciousness. Chichester: John Wiley.

Pécoud A (2010) Informing migrants to manage migration? An analysis of IOM's information campaigns. In: Geiger M and Pécoud A (eds) The Politics of International Migration Management. Hampshire: Palgrave Macmillan, pp. 184-201.

Schloenhardt A and Philipson E (2013) 'No to people smuggling': A review of Australia's antimigrant smuggling awareness campaigns. The University of Queensland Migrant Smuggling Working Group, Research Paper. Available at: https:/law.uq.edu.au/files/6729/SchloenhardtPhilipson-SoM-Awareness-Campaigns-2013.pdf

Ticktin M (2011) Casualties of Care: Immigration and the Politics of Humanitarianism in France. Berkeley, CA: University of California Press.

Tinti P and Reitano T (2016) Migrant, Refugee, Smuggler, Saviour. London: C. Hurst.

Vaughan-Williams N (2015) Europe's Border Crisis: Biopolitical Security and beyond. Oxford: Oxford University Press.

Walters W (2011) Foucault and Frontiers: Notes on the birth of the humanitarian border. In: Bröckling U, Krasmann S and Lemke T (eds) Governmentality: Current Issues and Future Challenges. New York: Routledge, pp. 138-164.

Watkins J (2015) Spatial imaginaries research in geography: Synergies, tensions, new directions. Geography Compass, 9(9): 508-522.

Watkins J (2017) Australia's irregular migration information campaigns: Border externalization, spatial imaginaries, and extraterritorial subjugation. Territory, Politics, Governance 5(3): 282-303. 